Snch is brief sccount of the alterations in the kidney sem the common name of Bright's disease. It has been difficult to bring so wide a subject into so short a space; and this will, it is hoped, account for some of the imperfections of the paper.

Birmingham, October 1855.

\section{CASE OF POISONING BY THE VAPOUR OF COKE: WITH REMARKS.}

By W. F. WADE, M.B., Resident Physician to the General Hospital, Birmingham.

[Read before the Birmingham and Midland Counties Branch.]

Thos. Stephens, a well developed lad, aged 13, was admitted into the General Hospital, Birmingham, under Dr. Fletcher, on Sunday, 25th March, 1855, at 2 o'clock, P.M., under the following circumstances. About an hour previous to his admission, he had been discovered in a sunall room in Floodgate Street, in bed, between his father and an elder brother aged 20 , both of whom were dead. The size of the room ras $430 \frac{1}{t}$ cubic feet: it contained a small stove, in which were the remains of a coke fire, quite extinguished. There was a hole in the wall, the size of one brick, communicating with a chimney of notoriously bad draught. I have not been able to ascertain whether the chimney of the stove had been properly fitted to this hole ; but it is very probable that it had not, as the stove was usually taken out of the room in the daytime. The boy, when discovered, was apparently in a quiet sleep, as were also his father and brother. He was removed into a neighbouring house, where he was immediately attended by Mr. Badger, of Bromsgrove Street, to whose prompt attention he is in a great measure indebted for his recovery. When first seen by Mr. Badger, he was (as I am informed by that gentleman) apparently asleep, with a moderately good pulse, and no appearance of congestion of the face or lips. Mr. Badger immediately dashed him with cold water, upon which he opened his eyes and stared about him, so that every one around thought that he would presently speak. Ile swallowed some gruel, a little brandy, and aromatic spirits of ammonia: some of these he vomited again. Instead, however, of becoming more conscious, he became again quite insensible, and was brought to the hospital, in somewhat less than an hour after his discovery.

On admission, he appeared almost inanimate; the face pale and cold; lips of a pale pink colour, their edges in two or three places slightly excoriated; limbs flaccid; pulse imperceptible, save an occasional feeble wave; heart's action scarcely perceptible; respiration quiet and unembarrassed, but very shallow; no stertor; lower part of chest much dilated, as in emphysema of the lung; the middle intercostal and suprasternal spaces drawn in during respiration; belly much distended hy tympanitis, and hard; pupils normal, perhaps rather contracted; eyes turned upward and inward, as in sleep. If left to himself, his respirations appeared to become shallower and shallower, as if about to cease completely. Dashing him on the face and chest with cold water roused his respiratory powers; but the effect was transient, and the process had to be frequently repeated. His pulse evidently increased in force and constancy when his breathing was more vigorous. Pressing forcibly and suddenly on the epigastrium induced inspiration; but as he was sick directly after one of these operations, I desisted from them; and, on making an effort to open his mouth, to rake the egesta out of his fauces, I found that his jaws were firmly fixed: I, however, forced them open, and got out some food which was lodged on the back of the tongue, so seriously impeding his breathing that, if it had not been promptly removed, it would probably have proved fatal. In the very act of vomiting, his pupils became widely dilated, and remained so afterwards. When he had been in the hospital for abont a quarter of an hour, I gave him a drachm of sulphuric æther, as an injection ser rec- tum : it did not seem to produce any other efiect than that of remoring the tympanitis, which it did completely and permanently. He was also cupped to a small amount over permanently. chest, without producing any obvious result. About an hour after his admission, I placed his feet and legs in mustard and water; this produced intense rigidity of the whole body, and his feet and legs became much redder and decidedly warmer afterwards. This rigidity redder and decidedly for several hours, alternating with persiste convulsions. The indication for treatment ras evidently to maintain his respiration till the poison should be eliminated: this was best done by constantly pinching him, and occasionally holding strong ammonis pinching him, and about three hours after admission, I applied large blister to his back, having previously administered an injection of three ounces of wine and four ounces of beef-tea: this latter was again repeated about nine o'clock, P.M. About half-past nine (i.e., seven and a half hours after admission), he uttered a slight groan; and on being asked, in a loud voice, "where it hurt him", he said, "My back". This was in allusion to the blister which was then rising. It was, howerer, still necessary to keep was then from time to time, as there was a tendency to deep sleep, bordering on coma, during which the respirations became shallow and slow; and it was not till half-past five the next morning that $I$ thought it safe to leave him. At nine the next morning, he was sensible, though still dull and heary; his tongue was covered with a thick white fur, except at the tip and edges, which were red and dry, with enlarged papillæ. During the night, he occasionally asked for drink, and appeared thirsty, but vomited everything except cold water. He passed water in bed about two hours after his admission, and again twice during the night. The consecutive fever increased during the second day; and on the third day his urine was albuminous, and in the evening bloody. On the fourth day, the albumen and fever had nearly disappeared, under the little or no recollection of the events which occurred on the day previous to the occurrence, being totally oblivious of the fact of his having received his wages on that (Saturday) afternoon.

Rexakks. Poisoning by the vapour of burning coke has not, so far as I am aware, been hitherto noticed ;* but from the fact that good coke is approximately pure carbon, prepared from coal instead of from wood, as well as from the history of the foregoing case, there is no reason to believe that any material difference exists between the symptoms of poisoning by coal charcoal and wood charcoal vapours. Coke, however, not unfrequently contains sulphur, the sulphureous acid gas arising from the combustion of which is an extremely energetic irritant poison, acting especially on the air passages. The gases resulting from the combustion of charcoal are carbonic acid and carbonic oxide (Guerard), carburetted hydrogen (Orfila), and probably a pyrogeneous acid (Hünefeld), whose nature is not accurately determined. These gases vary in relative amount, somewhat in proportion to the vigour of the ignition. As the fire had gone out in the present instance, it is clear that the victims had suffered from the combination of all these poisons.

These gases, though when undiluted they induce death by spasmodic closure of the glottis, and so act as a negative poison by the exclusion of oxygen, yet, when diluted with air, may be readily inspired, and then act as a positive sedative poison. This has been showu in different ways, and by different persons; but by none more distinctly than by Rolando, who, having found that the common land tortoise was not injured by the simple occlusion of one lung, contrived that one of these animals should breathe pure air by one lung, and carbonic acid gas by the other; and in a ferr hours it died.

- The only rase that 1 am aware of is that mentioned by Dr. Bird, in which o man was poisoned by the vapours arising from the burning of mixture of coal ashes with chalk. (Guy's Hospital Reports, No. VIII, April 1889.) 


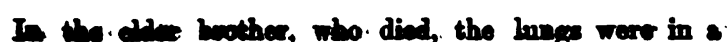

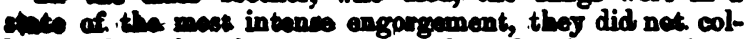
line Then the chest wase opened, and, when cut into, rymbled liver mare then lung. The brain also was consend in an extreme degree, the right side of the heart fill of fluid bleck blood, and the left side empty. There meno no sacus effusions in any of the cavities, and no emphream of the lungs. The eountenances of both father and son were placid and pale: the body of the former was not opened. I am indebted to Mr. Badger for all the foregeing information.

It is worth notice, that the room in which these three persons were sleoping contained only $430 \frac{1}{2}$ cubic feet, and was devoid of ventilation; whereas (according to Dr. Carpenter) the best authorities consider 800 cubic feet the minimum healthy allowance necessary for each individual, undess precautions be taken to insure free ventilation.

It is an extraordinarily interesting fact that this boy alone should have been found alive, while he lay between his father and brother. The two latter were, I am told, somewhat more elevated upon their pillows; but there could not have been more than a foot difference between their respective altitudes; and Dr. Taylor's experiments render it extremely improbable that this could have affected the diffusion of the gas. The father, however, was a notorious drunkard, and was drunk when he went to bed; the elder son had been playing cards in a public house till late the night before; and though it is not known that he was intoricated, yet the inference of his having been drinking is highly reasonable; this, at all erents, affords an explanation of the different termination of their cases to that of tho younger son, who had not been drinking; for it has been ascertained, that the imbibition of alcoholic fluids much diminishes the extrication of carbonic acid, and this diminution continues, till all the alcohol has passed of, when an unusual amount of carbonic acid is excreted, showing that the excrementitious carbon has been retained in the system, and not eliminated by another channel; and thus the father and elder brother not only imbibed carbon from the air, but had also a powerful obstacle to its elimination. I cannot undertake to say what difference (if any) is made by youth in these cases, neither can I offer any explanation of the differences which have been observed in the appearance of the face, which is sometimes livid, and the veins turgid, while in other cases (as the present one) no livor is present. The sudden and per.manent dilatation of the pupils in the act of vomiting, I have recently noticed in a case of intoxication where an emetic was administered.

The ether injection was employed with the riew of stimulating the left side of the heart, it being at first difficult to realise the fact that the deficiency of the pulse was altogether oring to obstructed pulmonary circulation, while the face and lips were so pale; but that this was so, there car be, of course, no doubt; and to relieve it, if possible, I applied the cupping glasses, but little blood could be obtained. Pinching, as a stimulant in narcotic poisoning, I had before had experience of, in the case of a little boy between three and four years of age, who had taken morphia, and whom it would have been impossible to walk about, but by keeping him continually crying for several hours, I was able satisfactorily to assure myself that he was not becoming comatose, and he recovered. The cold dashing, though very effective at first, became gradually less so, and it had, besides, the great disadvantage of lowering the external temperature, and so promoting internal congestion. Though the application of vapour of ammonia to the nares stimulatod him for the time, yet its first effect was to produce a spasm of the respiratory muscles and glottis, and this interfered with free respiration. It was found after a certain time that the respirations became, after each pinch, quick and shallow; this I took to be indicative of debility and exhaustion; for it has been shewn by Dr. Hutchinson that the resistance of the parietes of the chest to the entrance of air into the lung rapidly increases in a direct ratio to the quantity inepired; so that sapposing it wero decinch to inspire 100 cubic inobes of eir, it would require much less muscular effort to do 20 by two respirntions of 80 cubie inches each than by one of 100; hence there may bo two causes for increased rapidity of breathing, one inereased obstruction to entrance of air, as in croup, or progressive pneumonia, the other, diminished vital and muscular porer, as in fevers. There was no reason to suppose that the former existed here; and, to diminish the latter one, recourse was had to the injection of wine and beef-tea, and with satis. factory results.

On several occasions there seemed, from the rattles in the throat, to be a small collection of mucus in the largnx; but the sensibility was so low, that this did not induce coughing, hence it was needful to have recourse to some expedient. It is we!l known that the normal act of coughing consists of three parts: first, full inspiration; secondly, closure of the glottis; and thirdly, sudden opening of the glottis, and a violent expiratory effort; these steps were imitated as closely as possible; first, by producing a full inspiration by a sharp pinch; secondly, by pressing on the trachea, so as to prevent the exit of air for a short time, when the finger being suddenly withdrawn, a gush of air followed, and the mucus was expelled; at a later period, when the general sensibility was somewhat restored, rubbing on the larynx induced cough. I had previously had an opportunity of adopting a similar method in a case of aneurism of the aorta, which had produced paralysis of the muscles of the larynx, by pressing on the recurrent nerve; the man had considerable bronchitis, and great difficulty in getting up the mucus, from the imperfect closure of the glottis; by pressing his finger on the larynx, after taking a full inspiration, and suddenly withdrawing it, expectoration was much facilitated.

The blister was applied with the double intention of a general stimulant, and of acting more directly on the lungs, to relieve present congestion, and also to prevent excessive subsequent secretion into the bronchial tubes.

I have alluded to the resemblance of the shape and motion of the chest to those seen in emphysema of the lung, and I have no doubt that collapse of the lung, and probably emphysema, did actually exist in this case.

To those who are conversant with Dr. Gairdner's views on the causation of these pathological conditions, and bear in mind Dr. Reid's experiment on section of the pneumogastrics, the possibility of these conditions occurring in this case, and their causes will be obvious; more especially if we consider the chance of there having been sulphurous acid gas present in the air, and its well known power of producing spasm of the glottis; and I have recently seen them in an otherwise healthy man, who had been drowned.

Another very interesting phenomenon was observed ; after the boy had been in the hospital about an hour, his pulse failed, becoming exceedingly irregular, and almost absent, his breathing having become obstructed by vomiting; after a little time, I noticed that the pulse was entirely absent during inspiration, whilst during expiration, three or four beats in quick succession were observed; this continued for at least twenty minutes, during the whole of which time I had my hand on his pulse. This depended partly on the flow of blood through the lungs following immediately on the inspiration, and partly, probably, on the obstacle presented to the exit of any blood from the chest by its suction power, whilst the lungs were unable to expand freely, owing to the insufficient entrance of air, and their partial collapse. It is known that the venous pulse is much more distinct during expiration than inspiration, when, indeed, it is frequently quite imperceptible. The fact of consecutive fever is very interesting; it appears, when the blood is, from any cause, thrown entirely upon the internal organs, and there stagnates, as in the cold stage of ague and in Asiatic cholern, that if life is sufficiently prolenged reaction oceurs, which reaction is, in some degree, proporm 
tionate to the preceding stagmation. The occurrence of albuminuria during the secosdary forer is analogous to that which occurs in cholera.

Birmingham, October 1835

\section{INTERESTING OPERATION FOR BRONCHOCELE.}

By RICHARD HEY, Esq., Surgeon to the York County Hospital.

TThis paper, in a more extended form, was read before the York Medical Society in the winter of 1855.]

Althovg $\mathrm{it}$ would be foreign to our purpose were I to enter considerably into the general nature and treatment of bronchocele; yet in bringing forward the particular and interesting case to which I purpose calling attention at this time, it may not be amiss for a moment to glance at the nature and history of simple oronchocele, the varieties of it which render it more or less formidable, and its anatomical relations to the surrounding parts.

By bronchocele we understand an enlargement of the thyroid gland, which takes its name from its position on the thyroid cartilage of the trachea. In its normal condition the gland is so small as to present no prominence whatever. But this gland is subject to various morbid alterations, giving rise, in many cases, to not only great deformity, but also much inconvenience, either from its great volume or from its pressure on the surrounding parts. Bronchocele is said usually to make its appearance between the eighth and twelfth year and certainly affects females much more frequently than males. Although the enlargement is usually very slow and painles in its progress at first, so as frequently to be suffered withont control to go on enlarging for a considerable period, yet this is by no means always the case. The thyroid is subject, like other glands, to acute tumefaction from sudden inflammation, or even from improper diet. M. Coindet, of Geneva, mentions the circumstance of a regiment of young recruits, almost every man of which was attacked with sudden enlargement of the thyroid shortly after their arrival at Geneva, where they all drank water out of the same pump; on their quarters being changed, the gland soon regained its size in every instance.

Enlargements from simple hypertrophy may sometimes be so very considerable as not only to produce a lobulated tumour, occupying the entire throat, but even descending in front of the chest, and causing great obstruction to the respiration, as I have seen myself.

The enlargement may proceed from the development of accidental productions in its interior, even solid productions such as fibrous tissue, cartilage, or bone. I have myself seen the bronchocele consists of a large cyst; these, however, and others, are rare instances; and the last which I shall mention still rarer, happily, and that is enlargement from scirrhous degeneration, medullary sarcoma, etc.

It may be here incidentally observed, that errors in diagnosis will sometimes arise from enlargements produced by the thickening of the surrounding cellular tissue, or the enlargement of the lymphatic ganglia seated in the neighbourhood.

In the Provincial Medical and Surgical Journal for Sept. 19, 1849 (vide also Braithwaite's Retrospect, vol. $\times x$ ), I had the satisfaction of recording a case of bronchocele, for the cure of which, owing to obstructed respiration, I was induced to insert a seton. The success was complete; and the patient has continued well ever since.

I now take the liberty to lay before the Association the brief particulars of a case of bronchocele, in which it was necessary, in order to preserve the life of the patient, to open the windpipe, and to keep it open for a lengthened period. I am indebted to my friend Dr. Shann for some notes of the case up to the time when I visited the patient in consultation with him.
Dr. Shann sajs:- "I mow our patient (the daughter of a tradesman at York, aged about 20, of short stature and not very stout) for the first time on the 16th of March, 1853 very stout) for the frst tyspnoea, without cough. She had the purplish countenance and stooping of shoulders of an old asthmatic, and. as is usual in chronic cases of this kind, the consciousness of want of freedom in respiration was not the consciousness of want of freedom in respiration was not one to expect. The pulse was feeble, the extromities cool, and all the functions languid from the feeble state of circulation and general tendency to venous congestion. She had been suffering for some months from these symptoms, being more or less aggravated at intervals, not complaining greatly in the intermediate periods. After a careful stethoscopic examination, there was nothing met with in the condition of the heart or lungs, trachea or larynx, to indicate any primary affection of any of these organs, and I was led to the conclusion that the cause of the distressing symptoms was a small hard bronchocele, implicating both lobes, and the anterior portion of the thyroid gland. I preseribed under this impression, and the patient for a fer days seemed rather relieved. But about the eighth day from the time of my first seeing her the difficulty of breathing became suddenly and greatly aggravated, the respiration noisy and stridulous, apparently from a spasmodic affection of the laryngeal muscles. At first, there were periods of remission, and the patient gained some relief; but these became shorter by degrees, until, on the third day, it became so alarming as to threaten asphyxia; believing that an immediate operation afforded the only hope of arerting her impending fate, Mr. Hey was requested to see her in consultation with me." (I now take up the narrative in my own words.) We met, and I fully concurred in the view which Dr. Shann had taken of the case. As some further assistance seemed desirable, I requested Mr. Foll (the house-surgeon at the County Hospital) to give us his valuable aid. Whilst we were making some necessary preparations, I was unfortunately summoned into the country to a very urgent case, which placed me in a very uncomfortable dilemma. It was finally determined to try the effect of chloroform, in the hope of mitigating the spasn, and other remedies; and these failing, that $\mathbf{M r}$. Holl should open the trachea.

Early on the following morning a messenger was sent to the country, where I had been detained all night, to roquest my immediate attendance, which I was enabled to obey. I found that Mr. Holl had made several attempts to open the trachea, but without success. He had used the trocar and canula; and, as it appeared to me, every time he pressed upon the trachea it receded, and so the trocar failed to enter. I thought also that he made the attempt at a part of the trachea too low. I quickly cleared the blood from the wound, passed the forefinger of my left hand to the bottom, and felt for the cricoid cartilage. I then, with a common scalpel, guided by the finger, made a vertical slit through the two uppermost rings of the trachea, and the patient was at once relieved from her most perilous condition. (Here let me incidentally remark upon the value of the finger as a guide in some operations rather than the eyes.) A short pewter or zinc canula, somewhat curved, and with a broad wing, being introduced, was kept in its place by means of a bit of elastic, and the patient was soon in a comfortable state. The progress of the case was, on the whole, satisfactory. The canula was retained for about three months, and eventually was removed with perfect safety and success. One feature in this case particularly to be noticed was the satisfactory circumstance that the wound, kept open by the canula, acted as a seton, and the enlarged gland was eventually completely reduced; thereby serving to confirm (as Dr. Shann observes in a note appended) the favourable action of setons in bronchocele, which was well illustrated in the case to which I have already alluded.

REXARKs. I regret that my limits will not admit of my entering much into practical remarks upon this case; but 